\title{
Combined Lung Large Cell Neuroendocrine Carcinoma
}

National Cancer Institute

\section{Source}

National Cancer Institute. Combined Lung Large Cell Neuroendocrine Carcinoma. NCI

Thesaurus. Code C7267.

A subtype of large cell neuroendocrine lung carcinoma characterized by the presence of large neuroendocrine cells in combination with adenocarcinoma, squamous cell carcinoma, giant cell carcinoma and/ or spindle cell carcinoma. 